Original Article

\title{
Effects of interactive games on motor performance in children with spastic cerebral palsy
}

\author{
Amer A. AlSaif $\left.{ }^{1}\right)^{*}$, Samira Alsenany ${ }^{2)}$ \\ 1) Department of Physical Therapy, Faculty of Applied Medical Sciences, King Abdulaziz University: \\ P.O. Box 80324, Jeddah 21589, Saudi Arabia \\ 2) Public Health Department, Faculty of Nursing, King Abdulaziz University, Saudi Arabia
}

\begin{abstract}
Purpose] Motor control and muscle strength impairments are the prime reasons for motor behavior disorders in children with spastic cerebral palsy. These impairments lead to histological changes in muscle growth and the learning of motor skills. Therefore, such children experience reduced muscle force generation and decreased muscle flexibility. We investigated the effect of training with Nintendo Wii Fit games on motor performance in children with spastic cerebral palsy. [Subjects and Methods] Forty children with cerebral palsy spastic diplegia aged 6-10 years diagnosed with level-3 functional capabilities according to the Gross Motor Classification System (GMFCS) were enrolled. Participants were divided randomly into equal groups: group (A) that practiced with the Nintendo Wii Fit game for at least 20 minutes/day for 12 weeks and group (B) that underwent no training (control group). The Movement Assessment Battery for Children-2 (mABC-2) was used to assess motor performance, because it mainly involves motor tasks very similar to those involved in playing Nintendo Wii Fit games, e.g., goaldirected arm movements, balancing, and jumping. [Results] There were significant improvements in the subscales of the motor performance test of those who practiced with the Nintendo Wii, while the control group showed no significant changes. [Conclusion] Using motion interactive games in home rehabilitation is feasible for children with cerebral palsy.

Key words: Games, Motor, Pediatrics
\end{abstract}

(This article was submitted Feb. 13, 2015, and was accepted Mar. 14, 2015)

\section{INTRODUCTION}

Cerebral palsy $(\mathrm{CP})$ is a non-progressive developmental movement and posture disorder that occurs during fetal or infant development ${ }^{1}$. It is the most common physical developmental disability in childhood and encompasses a group of disorders of the development of movement and posture that cause activity limitations. These are attributed to non-progressive disturbances that occur in the developing infant brains ${ }^{2,3)}$. The impairment in $\mathrm{CP}$, including secondary impairments such as spasticity, muscle contracture, bone deformity, muscle weakness, and coordination disorders, is multifactorial and primarily affects the lower extremities, such as deficits in walking ability ${ }^{4}, 5$ ). The varying levels of impairment affecting children with $\mathrm{CP}$ can be described according to the Gross Motor Classification System (GMFCS $)^{6}$.

Physical inactivity in children with $\mathrm{CP}$ increases the risks of secondary problems such as pain, depression, social isolation, fatigue, pressure sores, and mobility limitations.

*Corresponding author. Amer A. AlSaif (E-mail: aalsaif@ kau.edu.sa)

(C2015 The Society of Physical Therapy Science. Published by IPEC Inc. This is an open-access article distributed under the terms of the Creative Commons Attribution Non-Commercial No Derivatives (by-ncnd) License $<$ http://creativecommons.org/licenses/by-nc-nd/3.0/> .
Children with CP suffer from motor and cognitive disabilities, which usually require a long-term, multifaceted, and multidisciplinary approach ${ }^{7)}$. Children with $\mathrm{CP}$ also tend to have lower endurance, muscular strength, and cardiorespiratory fitness than the general population ${ }^{8)}$. The consequences of chronic muscle imbalance and the resultant deformities can cause increasing disability with age ${ }^{9)}$.

One of the most significant problems faced by children with CP is defective postural control. Maintaining postural control, which is required to perform activities of daily living, is often a major challenge for children with CP. Active videogames such as those on the Nintendo Wii system may allow children with $\mathrm{CP}$ to perform many types of activities that are less affected by environmental barriers, which limit accessibility. Such videogames allow children with $\mathrm{CP}$ to perform self-directed, on-demand, and affordable physical activity $^{10)}$. The growing popularity of interactive gaming in healthcare is partially due to the belief that the fun and competitive aspects of videogames can direct a patient's focus away from the repetitive and mundane nature of rehabilitation exercises ${ }^{11}$. Some studies have evaluated interactive videogames, especially Wii Fit games, in different neurological diseases ${ }^{12)}$. However, no trials have demonstrated the benefits of Wii-based training for patients with $\mathrm{CP}^{13)}$. Nintendo Wii interactive games provide children with CP many health-related benefits such as improved postural control, mobility, postural stability, functional independence, and self-esteem ${ }^{14)}$. Therefore, this study determined the effects 
of interactive play with Nintendo Wii Fit games on motor performance in children with spastic CP.

\section{SUBJECTS AND METHODS}

Forty children diagnosed with CP spastic diplegia, their age ranged from 6-10 years old, with a matching functional capability of level 3 on the GMFCS, lower-limb muscle power no less than grade 4 according to the manual muscle test, and no fixed contractures in the lower limbs were recruited from the Pediatric Physical Therapy Department, King Abdulaziz University Hospital. Children with severe hearing loss, marked visual impairment, epilepsy, or autism were excluded. The patients were randomly divided into two study groups: group A played the Nintendo Wii Fit game for 20 minutes/day for 12 weeks, while group B did not (control group). This study was approved by the Faculty of Applied Medical Sciences Scientific Research Ethics Committee at King Abdulaziz University hospital, and informed consent was obtained from the parents or guardians of all children prior to participation.

Each child in group A was provided a Nintendo Wii Fit, which includes about 20 games, for use at home over a 12-week period. Measures reported in the present study, interviews with the parents/guardians about the families Measures rep with the intervention, and kinematic measurements of goal-directed arm movements were performed and will be presented in parallel papers.

The Movement Assessment Battery for Children-2 (mABC-2) was used to assess motor performance, because it mainly involves motor tasks very similar to those involved in playing Nintendo Wii Fit games, e.g., goal-directed arm movements, balancing, and jumping. This test is a new version of the $\mathrm{mABC}$ and was developed to be more appropriate for research. The mABC-2 targets children aged 3-16 years with coordination disorders and scores movement quality on the basis of 8 items included in 3 tests of manual dexterity, balance, and catching and aiming. The original mABC test was demonstrated to be both valid and reliable for assessing motor performance ${ }^{15}$. Upper-limb coordination was assessed by subtest 5:6 (touching a swinging ball) from the Bruininks-Oseretsky Test of Motor Proficiency (BOTMP). Finally, the one-minute walk test, the validity of which has been established, was performed to assess the general motor function of children with $\mathrm{CP}^{16}$ ).

The mean values of the investigated parameters were determined at the beginning and end of the study in both groups and compared by paired Student's t-tests. Meanwhile, comparisons between groups will be made using unpaired t-tests.

\section{RESULTS}

The present study evaluated the motor performance in response to training with Nintendo Wii Fit games in children with spastic CP. All children were able to practice the motion interactive games and were generally capable of handling the technology and setting up the gaming system. The motor performance scores of group A before and after the intervention are shown in Table 1 . The total $\mathrm{mABC}-2$ test score
Table 1. Motor performance test variables before and after Nintendo training of group(A)

(Unit: $\operatorname{LogS}$ )

\begin{tabular}{lcc}
\hline Test & Pre & Post \\
\hline mABC-2 total test score & $38.3 \pm 5.42$ & $44.1 \pm 5.21$ \\
Manual dexterity & $10.4 \pm 2.32$ & $17.3 \pm 1.25$ \\
Aiming \& catching & $12.5 \pm 2.91$ & $15.9 \pm 3.18$ \\
Balance & $12.1 \pm 3.12$ & $16.1 \pm 3.10$ \\
BOTMP 5:6 & $2.23 \pm 0.47$ & $3.78 \pm 0.39$ \\
1-minute walk test & $90.1 \pm 7.21$ & $98.8 \pm 6.75$ \\
\hline
\end{tabular}

Data are mean \pm SD. BOTMP 5:6: Bruininks-Oseretsky Test of Motor Proficiency subtest 5:6 (i.e., touching a swinging ball); mABC-2: Movement Assessment Battery for Children-2

Table 2. Motor performance test variables in group B (control group) (Unit: $\operatorname{LogS}$ )

\begin{tabular}{lcc}
\hline Test & Pre & Post \\
\hline mABC-2 total test score & $38.9 \pm 5.27$ & $39.1 \pm 5.16$ \\
Manual dexterity & $11.1 \pm 2.44$ & $11.3 \pm 2.42$ \\
Aiming \& catching & $12.8 \pm 3.15$ & $13.1 \pm 3.11$ \\
Balance & $12.5 \pm 3.62$ & $12.7 \pm 3.74$ \\
BOTMP 5:6 & $2.82 \pm 0.51$ & $3.12 \pm 0.66$ \\
1-minute walk test & $91.1 \pm 6.93$ & $91.8 \pm 6.82$ \\
\hline
\end{tabular}

Data are mean \pm SD. BOTMP 5:6: Bruininks-Oseretsky Test of Motor Proficiency subtest 5:6 (i.e., touching a swinging ball); mABC-2: Movement Assessment Battery for Children-2

Table 3. Motor performance parameters after the 12-week study period (Unit: $\log S$ )

\begin{tabular}{lcc}
\hline Test & Group A & Group B \\
\hline mABC-2 total test score & $44.1 \pm 5.21$ & $39.1 \pm 5.16$ \\
Manual dexterity & $17.3 \pm 1.25$ & $11.3 \pm 2.42$ \\
Aiming \& catching & $15.9 \pm 3.18$ & $13.1 \pm 3.11$ \\
Balance & $16.1 \pm 3.10$ & $12.7 \pm 3.74$ \\
BOTMP 5:6 & $3.78 \pm 0.39$ & $3.12 \pm 0.66$ \\
1-minute walk test & $98.8 \pm 6.75$ & $91.8 \pm 6.82$ \\
\hline
\end{tabular}

Data are mean \pm SD. BOTMP 5:6: Bruininks-Oseretsky Test of Motor Proficiency subtest 5:6 (i.e., touching a swinging ball); mABC-2: Movement Assessment Battery for Children-2

increased significantly after the intervention. Furthermore, subtest scores, included manual dexterity, aiming and catching, balance, one-minute walk test, and BOTMP 5:6 showed significant improvements. Meanwhile, there were no significant changes in any parameter in group B (Tables 2 and 3). Furthermore, the differences in parameters between groups at the end of the study were significant.

\section{DISCUSSION}

Children with CP are physically less active than normal children ${ }^{17)}$. Accordingly, children with $\mathrm{CP}$, who already have additional challenges, should be urged to perform more physical activity ${ }^{18)}$. Playing motion interactive videogames 
can be more physically demanding than traditional sedentary games ${ }^{19)}$. However, the extent of improvement in daily physical activity motion among physically disabled children due to interactive videogames remains unclear owing to a lack of research; furthermore, most existing studies are limited in size and do not provide strong evidence ${ }^{20}$. Two controlled studies and a few uncontrolled reports show positive results of motion interactive videogames on movement control ${ }^{21)}$. A few small studies also demonstrate motion interactive videogames can be useful for enhancing children be useful disposition, motivation to practice, and self-esteem ${ }^{22)}$. In the present study, the standing domains of gross motor function increased significantly after the intervention. This can be attributed to the regular physical activities performed by the children during the 12-week period, which is concordant with a study indicating virtual reality games such as the Nintendo Wii system improve arm and hand movements in children with $\mathrm{CP}^{23}$ ). The impairment in $\mathrm{CP}$, including secondary impairments such as spasticity, muscle contracture, bone deformity, muscle weakness, and coordination disorders, is multifactorial and primarily affects the lower extremities, such as deficits in walking ability ${ }^{24)}$. Moreover, one study demonstrates children with $\mathrm{CP}$ who play interactive videogames for 3 weeks show improvements in balance and motor performance ${ }^{25)}$. Children with $\mathrm{CP}$ may have impaired postural balance, which contributes to gait abnormalities ${ }^{26,27)}$. Furthermore, loaded sit-to-stand exercises improve basic motor abilities, functional muscle strength, and walking efficiency ${ }^{28-30)}$. In conclusion, Nintendo Wii Fit games improve the motor performance of children with spastic CP, warranting further study.

\section{ACKNOWLEDGEMENTS}

This project was funded by the Deanship of Scientific Research (DSR), King Abdulaziz University, Jeddah (grant no. 1434/142/502). The authors, therefore, acknowledge with thanks DSR for their technical and financial support.

\section{REFERENCES}

1) Himmelmann $\mathrm{K}$, Hagberg G, Beckung E, et al.: The changing panorama of cerebral palsy in Sweden. IX. Prevalence and origin in the birth-year period 1995-1998. Acta Paediatr, 2005, 94: 287-294. [Medline] [CrossRef]

2) Bax M, Goldstein M, Rosenbaum P, et al.: Executive Committee for the Definition of Cerebral Palsy: Proposed definition and classification of cerebral palsy. Dev Med Child Neurol, 2005, 47: 5717: 57105, 47: 57.

3) Binder H, Eng GD: Rehabilitation management of children with spastic diplegic cerebral palsy. Arch Phys Med Rehabil, 1989, 70: 482-489. [Medline] [CrossRef]

4) Gormley ME Jr: Treatment of neuromuscular and musculoskeletal problems in cerebral palsy. Pediatr Rehabil, 2001, 4: 5-16. [Medline]

5) Numthavaj P, Kliim-Due M, Rasmussen B, et al.: Individualized, homebased interactive training of cerebral palsy children delivered through the Internet. BMC Neurol, 2011, 11: 1-7. [CrossRef]

6) Benda $\mathrm{W}$, McGibbon $\mathrm{NH}$, Grant KL: Improvements in muscle symmetry in children with cerebral palsy after equine-assisted therapy (hippotherapy). J Altern Complement Med, 2003, 9: 817-825. [Medline] [CrossRef]

7) Massion J, Alexandrov A, Frolov A: Why and how are posture and move- ment coordinated? Prog Brain Res, 2004, 143: 13-27. [Medline] [CrossRef]

8) van der Heide JC, Begeer C, Fock JM, et al.: Postural control during reaching in preterm children with cerebral palsy. Dev Med Child Neurol, 2004, 46: 253-266. [Medline] [CrossRef]

9) Tarakci D, Ozdincler AR, Tarakci E, et al.: Wii-based balance therapy to improve balance function of children with cerebral palsy: a pilot study. J Phys Ther Sci, 2013, 25: 1123-1127. [Medline] [CrossRef]

10) Pompeu JE, Mendes FA, Silva KG, et al.: Effect of Nintendo Wiio Wii of Nintendo Wiido Wiiren with cerebral palsy: a pilot study. J Phys Ther Sci, 2014, 25: 2013-111.

11) Kim CJ, Son SM: Comparison of spatiotemporal gait parameters between children with normal development and children with diplegic cerebral palsy. J Phys Ther Sci, 2014, 26: 1317-1319. [Medline] [CrossRef]

12) Deutsch JE, Borbely M, Filler J, et al.: Use of a low-cost, commercially available gaming console (Wii) for rehabilitation of an adolescent with cerebral palsy. Phys Ther, 2008, 88: 1196-1207. [Medline] [CrossRef]

13) Biddiss E, Irwin J: Active video games to promote physical activity in children and youth: a systematic review. Arch Pediatr Adolesc Med, 2010, 164: 664-672. [Medline] [CrossRef]

14) Brown R, Sugarman H, Burstin A: Use of the nintendo wii fit for the treatment of balance problems in an elderly patient with stroke: a case report. Int J Rehabil Res, 2009, 32: 109-110. [CrossRef]

15) Smits-Engelsman BC, Fiers MJ, Henderson SE, et al.: Interrater reliability of the movement assessment battery for children. Phys Ther, 2008, 88: 286-294. [Medline] [CrossRef]

16) Croce RV, Horvat M, McCarthy E: Reliability and concurrent validity of the movement assessment battery for children. Percept Mot Skills, 2001, 93: 275-280. [Medline] [CrossRef]

17) McDowell BC, Kerr C, Parkes J, et al.: Validity of a 1 minute walk test for children with cerebral palsy. Dev Med Child Neurol, 2005, 47: 744-748. [Medline] [CrossRef]

18) Bjornson KF, Belza B, Kartin D, et al.: Ambulatory physical activity performance in youth with cerebral palsy and youth who are developing typically. Phys Ther, 2007, 87: 248-257. [Medline] [CrossRef]

19) Damiano DL: Activity, activity, activity: rethinking our physical therapy approach to cerebral palsy. Phys Ther, 2006, 86: 1534-1540. [Medline] [CrossRef]

20) Graf DL, Pratt LV, Hester CN, et al.: Playing active video games increases energy expenditure in children. Pediatrics, 2009, 124: 534-540. [Medline] [CrossRef]

21) Sandlund $M$, McDonough $S$, Häger-Ross $C$ : Interactive computer play in rehabilitation of children with sensorimotor disorders: a systematic review. Dev Med Child Neurol, 2009, 51: 173-179. [Medline] [CrossRef]

22) Snider L, Majnemer A, Darsaklis V: Virtual reality as a therapeutic modality for children with cerebral palsy. Dev Neurorehabil, 2010, 13: 120-128. [Medline] [CrossRef]

23) Shaffer RJ, Jacokes LE, Cassily JF, et al.: Effect of interactive metronome training on children with ADHD. Am J Occup Ther, 2001, 55: 155-162. [Medline] [CrossRef]

24) Reid DT: Benefits of a virtual play rehabilitation environment for children with cerebral palsy on perceptions of self-efficacy: a pilot study. Pediatr Rehabil, 2002, 5: 141-148. [Medline]

25) Al Saif AA, Al Senany S: Determine the effect of neck muscle fatigue on dynamic visual acuity in healthy young adults. J Phys Ther Sci, 2015, 27: 259-263. [Medline] [CrossRef]

26) Song CS: Effects of task-oriented approach on affected arm function in children with spastic hemiplegia due to cerebral palsy. J Phys Ther Sci, 2014, 26: 797-800. [Medline] [CrossRef]

27) Lee YS, Kim WB, Park JW: The effect of exercise using a sliding rehabilitation machine on the gait function of children with cerebral palsy. J Phys Ther Sci, 2014, 26: 1667-1669. [Medline] [CrossRef]

28) Kim Y, Lee BH: Clinical usefulness of child-centered task-oriented training on balance ability in cerebral palsy. J Phys Ther Sci, 2013, 25: 947-951. [Medline] [CrossRef]

29) Al Saif A, Alsenany S: Sensitivity and specificity of the amer dizziness diagnostic scale (adds) for patients with vestibular disorders. J Phys Ther Sci, 2015, 27: 91-96. [Medline] [CrossRef]

30) Al Saif AA, Alsenany S: The efficiency of the sideways stepping test in detecting unilateral vestibular hypofunction. J Phys Ther Sci, 2014, 26: 1719-1722. [Medline] [CrossRef] 